\title{
LXV. Observations on a paper entitled "some points in the meteorology of Bombay", read by colonel sabine to the British association in 1845, and published in the philosophical magazine for January 1846
}

\section{Thomas Hopkins Esq.}

To cite this article: Thomas Hopkins Esq. (1846) LXV. Observations on a paper entitled "some points in the meteorology of Bombay", read by colonel sabine to the British association in 1845 , and published in the philosophical magazine for January 1846, Philosophical Magazine Series 3, 29:196, 467-474, DOI: 10.1080/14786444608645544

To link to this article: http://dx.doi.org/10.1080/14786444608645544

曲 Published online: 30 Apr 2009.

Submit your article to this journal ¿

Џll Article views: 2 
cupies no space in solution. The solution which corresponds to this turning-point has a chemical strength of about $50^{\circ}$, and a specific gravity of nearly 1・05. Were a solution of sulphate of magnesia to be carefully made with proportions of salt and water corresponding to this stage of dilution, the result would appear to corroborate the late experiments of Dalton and of Messrs. Playfair and Joule, and thus a very accurate experiment might be made to support a very fallacious theory.

This last remark applies equally to many other substances whose examination is described in this memoir, and it shows the danger of drawing a sweeping conclusion from the results of any single experiment, however accurately performed. Thus, in the case of sulphuric acid, if we were to adopt the rash principle of deciding upon the atomic measure from the results of a single experiment, we could prove the atomic measure of that acid to be 2 volumes, or 1 volume, or nothing, or less than nothing; in short, anything we pleased between plus 34 septems and minus 68 septems; for we could pick out an accurate experiment to yield any numerical product that best suited a given purpose within those limits.

LXV. Observations on a Paper entitled "Some Points in the Meteorology of Bombay," read by Colonel Sabine to the British Association in 1845, and published in the Philosophical Magazine for January 1846. By Thomas Hopkins, Esq ** WITH our imperfect knowledge of the influences which determine the general movements of the atmosphere, the semi-diurnal fluctuations of the barometer become interesting objects of study, as it appears not improbable that the causes which produce the daily alterations of that instrument may determine its casual and irregular fluctuations, as well as the general movements of the atmosphere itself.

That the diurnal fluctuations of the barometer are in some way connected with alterations of temperature, is apparent from their relation to the daily variation of solar influences; but the precise way in which these influences operate is not equally clear. A rise of temperature, such as that which takes place in the morning, there can be no doubt tends in some degree to lighten the atmosphere, and to produce a fall of the barometer in the part; but at the same time it increases evaporation of aqueous vapour from wet surfaces, the effect of which is to add to the weight of the whole atmosphere in the locality, to the extent of the addition of the vapour that is

* Communicated by the Author. 
thereby produced. Thus through solar influence two caisses are brought into operation at the same time, which produce opposite effects on the pressure of the atmosphere, - the one tending to make it lighter, the other heavier.

By a careful registration of the hourly alterations of both the wet and the dry-bulb thermometers, we may obtain,- - first, a knowledge of the daily changes of temperature near the surface of the earth; and secondly, of the extent to which evaporation keeps down the temperature in the wet-bulb thermometer: and from the extent to which temperature is thus kept down in the wet-bulb thermometer, we may infer the energy with which vapour is produced from wet surfaces, and thrown into the air to increase the aggregate atmospheric pressure. If the daily fluctuations of the barometer were produced by these two influences alone, those influences might, without much difficulty, be traced to their results, and their separate as well as their joint effects might be exhibited in the movements of the barometer.

But in most of the cases where registrations of the two instruments have been furnished, the barometric fluctuations have not been found to accord with the increase of vapour produced by evaporation. From sunrise until about ten o'clock in the morning evaporation generally proceeds with considerable energy, and a consequent increase of vapour pressure may be traced in a rise of the barometer; but after that time any increase of vapour pressure on the barometer ceases: yet that evaporation continues active afterwards is shown by the effect that is produced by it on the wet-bulb thermometer. What then becomes of this additional vapour? Or why does it not further raise the mercury of the barometer?

About ten o'clock in the morning the barometer ceases to rise, and shortly afterwards begins to fall, and it continues falling until four in the afternoon, although the cooling of the wet-bulb thermometer by evaporation shows that from ten until one or two o'clock, the time of the highest temperature, vapour must be passing into the atmosphere in increasing quantities! and the vapour must be presumed to accumulate in the atmosphere until four o'clock, as the evaporation generally continues active up to that hour, and no decline of the dew-point indicates the condensation of any portion of the vapour thus produced. Now if increase of vapour had raised the barometer up to ten o'clock, why should not a further accumulation of vapour after that hour raise the barometer still higher? The fall of the barometer after ten o'clock, it is evident, cannot be accounted for from the operation of the causes named. 
That mere alterations of thermometric temperature and of vapour pressure, either jointly or separately, do not produce the fall of the barometer from ten in the morning to four in the afternoon, may be proved by facts when the registration of the wet-bulb thermometer is given; but unfortunately this is seldom done. In the Plymouth report by Mr. S. Harris that registration is to be found; and there it may be seen that the temperature theory does not harmonize with the facts. But in the account of the meteorology of Bombay, as given by Colonel Sabine, there is no notice of that instrument. Vapour pressure, as ascertained by the derv-point, is there exhibited as one of the two causes which determine barometric fluctuation,--thermometric temperature being considered the other; and these two causes are by him represented as sufficient to account for the facts and form the basis of his theory, which for convenient reference I have called " the temperature theory."

In remarking at present on the Bombay report, I propose to confine myself principally to objections to the theory advanced to account for the phænomena, and do not intend to show in a detailed form what were the real causes in operation, seeing that all the facts required are not furnished. Had an account of the evaporation that took place been given, I would have attempted to trace the vapour that was produced after ten o'clock, until it was condensed in the higher part of the atmosphere and converted into cloud, with the effects of that conversion on the barometer; but without the registration of the wet-bulb thermometer this cannot be satisfactorily done.

In the report the facts contained in the following table are given for Bombay in 1843, - of mean temperature, mean barometric pressure, mean tension of vapour, and mean gaseous pressure at every second hour.

\begin{tabular}{|c|c|c|c|c|}
\hline $\begin{array}{c}\text { Hour of mean } \\
\text { Bombay time. } \\
\text { Astronomical } \\
\text { reckoning. }\end{array}$ & Temperature. & Barometer. & $\begin{array}{c}\text { Dew-point, or } \\
\text { Tension of } \\
\text { Vapour. }\end{array}$ & $\begin{array}{c}\text { Gaseous } \\
\text { Pressure. }\end{array}$ \\
\hline & & in. & in. & in. \\
16 & $78 \cdot 9$ & $29 \cdot 778$ & $0 \cdot 761$ & $29 \cdot 017$ \\
18 & $78 \cdot 4$ & $29 \cdot 805$ & $0 \cdot 750$ & $29 \cdot 055$ \\
20 & $79 \cdot 6$ & $29 \cdot 840$ & $0 \cdot 766$ & $29 \cdot 074$ \\
22 & $81 \cdot 8$ & $29 \cdot 852$ & $0 \cdot 771$ & $29 \cdot 081$ \\
0 & $83 \cdot 2$ & $29 \cdot 817$ & $0 \cdot 768$ & $29 \cdot 049$ \\
2 & $84 \cdot 1$ & $29 \cdot 776$ & $0 \cdot 795$ & $28 \cdot 981$ \\
4 & $83 \cdot 9$ & $29 \cdot 755$ & $0 \cdot 800$ & $28 \cdot 955$ \\
6 & $82 \cdot 3$ & $29 \cdot 774$ & $0 \cdot 802$ & $28 \cdot 972$ \\
8 & $81 \cdot 2$ & $29 \cdot 806$ & $0 \cdot 801$ & $29 \cdot 005$ \\
10 & $80 \cdot 3$ & $29 \cdot 825$ & $0 \cdot 780$ & $29 \cdot 045$ \\
12 & $79 \cdot 8$ & $29 \cdot 809$ & $0 \cdot 775$ & $29 \cdot 034$ \\
14 & $79 \cdot 4$ & $29 \cdot 786$ & $0 \cdot 766$ & $29 \cdot 020$ \\
\hline
\end{tabular}




\section{Mr. T. Hopkins on the Meteorology of Bombay.}

This table commences at four o'clock in the morning, that hour being generally one of the turning-points in the semidinnal movements of the barometer. From four to ten that instrument rises from $29 \cdot 778$ to $29 \cdot 852$ inches. Now this rise, on the temperature theory, must be considered to have been produced either by a reduction of temperature, as measured by the thermometer near the surface of the earth, or by an increase of the pressure of aqueous vapour, as ascertained by the dew-point; or by both those influences acting together, and producing the rise of the barometer, as a general result.

We find, however, that during the first two hours, that is from four to six o'clock, the thermometer fell from $78^{\circ} \cdot 9$ to $78^{\circ} \cdot 4$, being a fall of $\cdot 5$; and the tendency of this fall most undoubtedly was to produce a rise of the barometer; but at the same time the pressure of vapour, as indicated by the dew-point, declined so much as firom $\cdot 761$ to $\cdot 750$, or $\cdot 011$. Now this comparatively large reduction of vapour pressure is evidently the greater of the two disturbing forces, and the result of the action of both the forces, according to the theory, ought to be a fall of the barometer. But instend of falling the barometer rose during the two hours from $29 \cdot 778$ to $29 \cdot 805$, or 027 ; showing that the movement of that instrument in this time was the reverse of what would have occurred if the temperature theory was true.

From six to ten o'clock, the remainder of the first period of six hours, the barometer continued rising, and passed from 29.805 to 29.852 , making a rise in these four hours of $\cdot 047$, whilst the thermometer rose from $78^{\circ} \cdot 4$ to $81^{\circ} \cdot 8$, or $3^{\circ} \cdot 4$, and the dew-point increased from $\cdot 750$ to $\cdot 771$, or $\cdot 021$. Thus of the whole six hours we find that, during the first two, a fall of temperature of $\cdot \cdot \cdot 5$ fproduced a rise of and a fall of the dew-point of $\cdot 011$ the barometer of $\} .027$ which would appear to prove, and as far as the facts given go, do prove, that the small fall of temperature had the greater influence on atmospheric pressure, as the barometer rose $\cdot 027$ while both influences were in operation.

But in the following four hours, from six to ten o'clock, a rise of the thermometer of $3^{\circ} \cdot 4$ and a rise of the dew-point of .021 , were accompanied by a rise of the barometer of $\cdot 047$; or put into tabular form, say that

$\left.\begin{array}{l}\text { a rise of temperature of } 3^{\circ} \cdot 4 \\ \text { and of the dew-point of } \quad .021\end{array} \quad \begin{array}{c}\text { produced a rise of } \\ \text { the barometer of }\end{array}\right\} \cdot 04.7$ that is between four and six o'clock, when the fall of the dewpoint is great compared with the fall of temperature, and the two acting together ought to produce a fall of the barometer, that instrument rises! But between six and ten the tempera- 
ture increases greatly, as much as nearly seven times the amount that it previously fell, whilst the dew-point, although it also rises, does not rise to quite double the extent that it fell in the two hours; yet notwithstanding these great alterations, amounting to complete reversals of the two influences that are in operation, the barometer continues to rise, and attains an increase of 047 . These facts, however, taken together, show that temperature, as mensured by the thermometer near the surface of the earth, produces little comparative effect on the amount of atmospheric pressure; and that the alteration of vapour pressure must have had much greater influence than alteration of temperature as measured by the thermometer, and must have produced the rise of the barometer from six to ten o'clock.

Proceeding to the next six-hour stage of the daily fluctuations of the barometer, we find that from ten to two o'clock, the first four of these six hours, temperature advances $2^{\circ} \cdot 3$, and reaches its highest point for the day at the last-named hour; and the dew-point, indicating vapour pressure, also rises as much as 024 . Here it appears that vapour pressure increases so much as $\cdot 024$, whilst temperature advances only $2^{\circ} .3$; alteration of vapour pressure therefore should, in accordance with what had occurred previously, be now more powerful than alteration of temperature, and should further increase the whole atmospheric pressure, and cause the barometer to rise higher than the point it had previously reached, as the theory we are examining teaches it ought to do; but instead of rising the barometer falls no less than 076 ; so that from six to ten o'clock, whilst

a rise of temperature of $3^{\circ} \cdot 4$

and a rise of the dewpoint of . . . .021 in the following four hours, from ten to two o'clock, a rise of temperature of $\cdot .20 .3$
and a rise of the dew-point of $\cdot 024$$\left\{\begin{array}{l}\text { produced a fall of } \\ \text { the barometer of }\end{array}\right\} \cdot 076$ Thus, where the vapour pressure is relatively weak, we see that the barometer rises; and where it is relatively strong the barometer sinks, - being the reverse of that which must have taken place if the temperature theory were correct.

Again, from two to four o'clock P.M. the temperature sank .2 and the dew-point rose $\cdot 005$. Thus during these two hours the alterations which took place in both the temperature and the dew-point were such as from the operation of each of their influences ought, on the temperature theory, to have caused the barometer to rise. But it did not rise; on the contrary it fell, -no less than 021 . These facts prove most 
conclusively, that the fluctuations of the barometer in the times named were not produced by alterations of temperature and of vapour pressure, as they are exhibited to us by the thermometer and the dew-point.

It should be borne in mind, that it is the fall of the barometer from ten in the morning to four in the afternoon while evaporation, as shown by the wet-bulb thermometer, is active, for which we have particularly to account. Temperature rises while vapour augments up to ten o'clock in the morning, and at the same time the barometer rises; but after ten, though the same two causes continue in operation, yet the barometer falls, and continues falling until four in the afternoon. Now why should the same causes be supposed to produce one effect up to ten o'clock, and another, of an opposite character, for six hours after that time? This is the question that has to be answered. The temperature theory, so far from accounting for the occurrence of these phænomena, is directly opposed to them, and utterly fails to account for the fall of the barometer from ten to four o'clock.

The alterations which took place in the subsequent twelve hours present additional evidence of the inadequacy of the temperature theory to account for the semi-diurnal fluctuations of the barometer; but as they are not equally palpable with those already examined, it is unnecessary to go into a consideration of them.

In furnishing such accounts as those of the meteorology of Bombay, that which is required in order more fully to elucidate the subject is, that in addition to the usual registrations the temperature of the wet-bulb thermometer should be given. This would enable us to trace the vapour that is thrown by evaporation into the atmosphere in the hottest part of the day. Could we do this, there seems no doubt that it would be found ascending in the atmosphere until it became condensed and formed cloud; and the heat liberated by this condensation, as I have elsewhere explained, is the real cause of the diminished pressure of the atmosphere in the locality during the six hours that the barometer falls.

In a note appended to the paper published in the Philosophical Magazine for January 1846, Colonel Sabine gives an extract from a paper received from M. Dove, which is stated to have been read in the Academy at Berlin, in which it is said that "at Catherinenbourg and Nerlchinsk, on the mean of several years, and at Barnaoul, in the years 1838 and 1840, the mean diurnal barometric curve itself exhibits but one maximum and one minimum in the twenty-four hours; the maximum coinciding nearly with the coldest and the minimum 
with the hottest hours of the day." But the Colonel afterwards shows from other accounts, that there is a very small morning maximum in the locality named, which occurs between the hours of eight and eleven A.M. This he attributes to the pressure of additional aqueous vapour, and he seems to think such a fact confirmatory of the correctness of his views. If however an increase of vapour up to eleven o'clock could raise the barometer, why should not that instrument rise further after that hour? Had we a registration of the wet and dry-bulb thermoneters and of the dew-point, it is to be presumed that proof would be furnished that evaporation was more active after eleven than it had been before that hour, and that there was no decline of the dew-point until a much later period of the day. The vapour that must be presumed to have passed into the atmosphere in the hottest part of the day, must either have added to the previous pressure on the barometer and raised it, or it must have been condensed, and warmed the higher part of the atmosphere. As it did not produce the former effect, in the absence of information we may assume that it produced the latter.

In the extract given from M. Dove's communication we have no account of the daily range of the barometer, or of the extent of its fall during the day, though that is the most interesting fact to be ascertained; this is to be regretted. If a sun-heated surface is the cause of the atmosphere becoming so much lighter in the day than it is in the night, the atmosphere at the places named by $M$. Dove ought to be rendered much lighter every day than it was in the previous night, seeing that the temperature of the day is raised greatly above that of the night; the daily range of the barometer should consequently, on the Colonel's theory, be extensive. Is it so? If it is not, it is so far evidence against the theory.

It is stated in the Russian account that in the places pointed ont there is one maximum and one minimum, the maximum nearly coinciding with the coldest, and the minimum with the hottest hours of the day. And the conclusion drawn seems to be, that alteration of surface temperature is the sole cause of the movement of the barometer: hence the desirableness of showing the extent of that movement. If it be great, it will so far show that the heating of the surface of the earth by the sun could materially diminish atmospheric pressure. But if the daily movement of the barometer is found to be small, it will present presumptive evidence that daily surface-heating has no important local effect on the weight of the atmosphere. A full account of the registrations in this part of the world Phil. Mag. S. 3. Vol.29. No. 196. Dec. 1846. 2 K 


\section{On the Bands formed in the Prismatic Spectrum.}

might furnish the means of proving either the correctness or the fallacious nature of the temperature theory, to which objections have been advanced in this paper.

LXVI. Note on the Bands formed by Partial Interception in the Prismatic Spectrum. By Professor Poweld.*

IN a communication to the Physical Section of the British Association at its last meeting, I offered some remarks on the question relative to the above-named singular phænomena; in particular stating one experimental result, originally announced by Sir D. Brewster, which I had fully verified, and which had appeared to him at variance with the theory of Mr. Airy, along with another fact of my own detection, viz. that when the aperture was contracted the bands became more vivid. No one, I trust, was led, from the manner in which my remarks were reported, to imagine that I brought this forward in any spirit of hostility to the theory. On the contrary, I never entertained a doubt (and I believe I expressed this at the meeting) that upon every ground of analogy and probability the theory would still be found adequate to the solution of the difficulty: I fully expected that it wanted only the introduction of some further condition or modification, though, as it appeared, no such condition had yet been pointed ont. It seems that this essential condition, now first brought to notice by the Astronomer Royal in his paper in the last Number of this Journal, had in some way escaped the attention of all those who had read his previous papers in the Philosophical Transactions, ever since the first announcement of Sir David Brewster's objection at the British Association at Manchester, $1842 \dagger$, and notwithstanding that his detailed repetition of that objection was fully discussed at the Cambridge meeting in 1845. And I am anxious to seize this opportunity of acknowledging and recording my conviction, that it entirely supplies what was wanting to relieve the theory of the objection which seemed to beset it; and that this has proved but one more of those already numerous and striking instances, in which what seemed a most formidable difficulty in the undulatory theory of light has been converted into one of its strongest points of support.

Oxford, November 2, 1846.

* Communicated by the Author.

$\uparrow$ See Report, Sectional Proceedings, p. 12. 